\title{
PATRONES DE ADHERENCIA DE CEPAS DE Escherichia coli DIFUSAMENTE ADHERENTE (DAEC) PROVENIENTES DE NIÑOS CON Y SIN DIARREA
}

\author{
Maribel Riveros ${ }^{1, a}$, Francesca Barletta1,b, Martín Cabello ${ }^{1, c}$, David Durand ${ }^{1, a}$, Erik H. Mercado ${ }^{1, a}$, \\ Carmen Contreras ${ }^{1, b}$, Fulton P. Rivera ${ }^{1, c}$, Susan Mosquito ${ }^{1, b}$, Ángela Lluque ${ }^{1, a}$, Theresa J. Ochoa ${ }^{1,2, d}$
}

\begin{abstract}
RESUMEN
Introducción. Las E. coli de adherencia difusa (DAEC) son el sexto grupo de E. coli diarrogénicas reconocidas. Su asociación con diarrea es controversial. No se conoce la variabilidad en los patrones de adherencia de cepas clínicas. Objetivos. Comparar los patrones de adherencia entre cepas aisladas de niños con y sin diarrea. Materiales y métodos. Se analizó 31 cepas DAEC, 25 de diarrea y 6 de niños asintomáticos (control) aislados de un estudio de cohorte de niños menores de 12 meses en el cono sur de Lima. Las DAEC fueron identificadas por PCR (gen daaD). Se evaluó el patrón y grado de adherencia en cultivos de células HEp-2; la polimerización de actina se evaluó por la prueba de coloración de fluorescencia de actina (FAS); y la motilidad se evaluó por métodos convencionales microbiológicos. Resultados. El patrón de adherencia difusa se encontró en el $88 \%$ de muestras de diarrea y en el 100\% de muestras control. La cantidad de bacterias adheridas por célula fue significativamente menor en las muestras de diarrea $(p<0,05)$. Sin embargo, la polimerización de actina fue mayor en las muestras de diarrea (60\% frente a 17\%). La prueba de motilidad fue positiva en el $60 \%$ de las cepas de diarrea y en el total de muestras control. Conclusiones. Nuestros hallazgos sugieren la existencia de diferencia en los patrones de adherencia, polimerización de actina y motilidad entre cepas de DAEC correspondientes a los grupos de diarrea y control. La significancia de estos resultados debe confirmarse con mayor número de cepas, así como la determinación de los genes de virulencia en las cepas.
\end{abstract}

Palabras clave: Escherichia coli de Adherencia Difusa; Diarrea; Niño; Adhesión Bacteriana; (fuente: DeCS BIREME).

\section{ADHESION PATTERNS IN DIFFUSELY ADHERENT Escherichia coli (DAEC) STRAINS ISOLATED FROM CHILDREN WITH AND WITHOUT DIARRHEA}

\begin{abstract}
Introduction. Diffusely adherent E. coli (DAEC) is the sixth recognized group of diarrheagenic E. coli. However, its association with diarrhea remains controversial. Variability in the adherence patterns of clinical strains is unknown. Objectives. To compare the adherence patterns between strains isolated from children with and without diarrhea. Materials and methods. A total of 31 DAEC strains were analyzed, 25 from children with diarrhea and 6 from asymptomatic (control) children, isolated from a cohort study of children under one year of age in the southern districts of Lima. DAEC were identified by PCR (daaD gene). The pattern and adherence score in HEp-2 cell culture were evaluated, Actin polimerization was determined by fluorescence actin staining (FAS) and motility was evaluated by conventional microbiology methods. Results. Diffuse adherence pattern was found in $88 \%$ of diarrhea samples and in the total of control strains. The number of bacteria adhered per cell was significantly lower in diarrhea samples $(p<0.05)$. However, actin polymerization was greater in diarrhea samples (60\% vs. $17 \%$ ). Motility test was positive in $60 \%$ of the diarrhea samples and in all control samples. Conclusions. Our findings suggest a difference between adherence patterns, actin polymerization and motility between DAEC strains corresponding to diarrhea and control groups. The significance of these results must be confirmed with a bigger number of strains and determining the presence of virulence genes in the strains.
\end{abstract}

Key words: Diffusely Adherent Escherichia coli; Diarrhea; Child; Bacterial Adhesion (MeSH NLM).

\section{INTRODUCCIÓN}

La diarrea es una de las principales causas de muerte en niños menores de cinco años de edad en el mundo (1). Aunque la mortalidad de la enfermedad diarreica está disminuyendo, la incidencia de diarrea no disminuye.
Por tal motivo, para obtener medidas preventivas es esencial describir la historia natural y la importancia relativa de varios agentes diarrogénicos.

Las cepas de E. coli diarreogénicas son una de las causas más importantes de diarrea aguda y persistente

\footnotetext{
Instituto de Medicina Tropical "Alexander von Humboldt”, Universidad Peruana Cayetano Heredia, Lima, Perú.

2 University of Texas School of Public Health, Houston, Texas, Estados Unidos.

a Biólogo; ${ }^{\text {b }}$ Magíster en Biología Molecular y Bioquímica; c Tecnólogo Médica; d Médica Infectóloga Pediatra
}

Recibido: 17-01-11 Aprobado: 02-03-11 
en niños de países en vías de desarrollo ${ }^{(2)}$. Actualmente se reconocen seis grupos en base a criterios clínicos, epidemiológicos y moleculares: $E$. coli enteropatogénica (EPEC), E. coli enterotoxigénica (ETEC), E. coli enteroinvasiva (EIEC), E. coli productora de shiga toxina (STEC), E. coli enteroagregativa (EAEC) y $E$. coli de adherencia difusa (DAEC). Inicialmente fueron clasificadas según su patrón de adherencia a células HEp-2 como: adherencia localizada (LA), adherencia agregativa (AA) y adherencia difusa (DA) ${ }^{(3,4)}$. Esta última adherencia es presentada por la $E$. coli de adherencia difusa (DAEC), la cual tiene una asociación muy controversial con los episodios diarreicos ${ }^{(5)}$.

La adhesión es el primer paso para mantener a los miembros de la microflora normal en el intestino; sin embargo, es también la primera etapa crítica en todas las infecciones diarreicas causadas por cepas patógenas de E. coli. Es importante, por lo tanto, comprender las características que subyacen a la adhesión de $E$. coli difusamente adherente ${ }^{(6)}$. Estudios morfológicos han descrito que las cepas DAEC generan un fenotipo inusual de adherencia celular sobre el cultivo de células HEp-2, observándose la inducción de algunas proyecciones de la membrana celular ${ }^{(7,8)}$, la prueba de FAS (tinción fluorescente para actina, por sus siglas en inglés) es una técnica alternativa que ha sido ampliamente usada para la identificación de la alteración histopatológica en el intestino, conocida como lesión A/E (adherencia y borramiento) causada por EPEC. La lesión se lleva a cabo mediante un mecanismo de virulencia complejo, que induce la degeneración de las microvellosidades y altera la morfología normal de la región apical del enterocito ${ }^{(9)}$.

Muchos procariotas son móviles y esta capacidad de movimiento independiente se debe con frecuencia a una estructura especial, el flagelo. Un número creciente de estudios han incluido la motilidad mediada por los flagelos en la virulencia, como en la adhesión, la invasión y la respuesta proinflamatoria en bacterias Gram negativas. Un patrón asociado a cepas DAEC fue la liberación de interleuquina 8 (IL-8) y su asociación con la motilidad ${ }^{(10)}$. La prueba de la movilidad entonces puede ser un método sencillo a tomar en cuenta para predecir la capacidad patogénica de DAEC aislados en laboratorios.

El objetivo principal de este estudio fue determinar si existen diferencias en la distribución de bacterias adheridas de cepas DAEC provenientes de niños con y sin diarrea, como también describir y comparar las características del patrón de adherencia, la variación en los patrones de polimerización de actina y la motilidad de las diferentes cepas de $E$. coli de adherencia difusa provenientes de niños con y sin diarrea.

\section{MATERIALES Y MÉTODOS}

\section{CEPAS}

Un total de 31 cepas de DAEC confirmadas por un PCR múltiple en tiempo real (11) fueron colectadas de 1034 niños seguidos desde los 2 a 12 meses de edad de un estudio de cohorte de vigilancia pasiva de diarrea conducido en el distrito de Chorrillos, Lima, durante el 2006 y $2007^{(12)}$. En este estudio se aislaron 25 cepas DAEC de pacientes con diarrea y seis de pacientes sin diarrea.

\section{LÍNEA CELULAR Y CONDICIONES DEL CULTIVO}

Las células HEp-2 fueron cultivados en medio esencial mínimo Eagle's (DMEM) enriquecido con L- glutamina (5 $\mathrm{mg} / \mathrm{mL})$, piruvato $(5 \mathrm{mg} / \mathrm{mL}), \operatorname{SBF}(10 \%)$, penicilina $(200 \mu \mathrm{g} / \mathrm{mL})$ y estreptomicina $(200 \mu \mathrm{g} / \mathrm{mL})$ a $37^{\circ} \mathrm{C}$ en $5 \%$ de $\mathrm{CO}_{2}$.

\section{ENSAYO DE ADHERENCIA}

Se colocó $1 \mathrm{~mL}$ de monocultivos HEp-2 a una densidad de $10^{5}$ células $/ \mathrm{mL}$, en placas de 24 pocillos con cubreobjetos de $13 \mathrm{~mm}$ de diámetro para luego incubarse durante 24 horas a $37{ }^{\circ} \mathrm{C}$ y $5 \% \mathrm{CO}_{2}$, procedimiento detallado por Donnenberg y Nataro ${ }^{(6)}$. Pasada las 24 horas, este medio fue reemplazado por $1 \mathrm{~mL}$ de medio de adherencia más $1 \mathrm{~mL}$ del cultivo bacteriano a una densidad de $10^{7}$ bacterias $/ \mathrm{mL}$ incubándose por tres horas a $37^{\circ} \mathrm{C}$, siendo la relación de infección bacteria-célula en una proporción de 100:1. Terminado el periodo de incubación se lavó con buffer fosfato salino de 2-3 veces, se fijó con metanol absoluto, el cubreobjeto fue trasladado rápidamente a una lámina de vidrio donde se realizó una tinción Giemsa, para luego realizar la evaluación microscópica. La lectura fue revisada por el observador sin conocer el tipo de muestra a la que pertenecía.

\section{PATRÓN DE ADHERENCIA DIFUSA A CÉLULAS HEp-2}

La interpretación del ensayo de adherencia se realizó considerando el patrón de adherencia difusa (DA) según las consideraciones mencionadas por Donnenberg y Nataro ${ }^{(6)}$, se interpretó la lectura de cada lámina de la siguiente manera:

Bacteria sin adherencia. Determinado como organismos individuales en el cubreobjeto o células sin bacterias.

Adherencia localizada. Bacterias visualizadas mediante observación microscópica (1000x), donde las células HEp-2 tenían microcolonias localizadas.

Adherencia difusa. Las bacterias son vistas en todo el entorno o cubriendo la superficie de la célula. 


\section{CUANTIFICACIÓN DE ADHERENCIA A CÉLULAS HEp-2}

Dos experimentos iniciales con cepa DAEC-CG33 (control del patrón DA) permitieron la cuantificación de las bacterias adheridas bajo el microscopio, para luego categorizar las células según la cantidad de bacterias adheridas como: 0, 1-50, 50-100 y >100 bacterias por célula. En las 31 cepas se realizaron tres ensayos por duplicado. Se analizó un total de 300 células por cubreobjeto.

\section{PRUEBA DE FAS (TINCIÓN FLOURESCENTE PARA ACTINA)}

Con modificaciones según el método de Knutton et al. ${ }^{(13)}$, esta prueba se realizó con los mismos procedimientos iniciales del ensayo de adherencia descrito previamente, variando en el proceso de fijación con formalina al $20 \%$ y la tinción con BODYPI (tiñendo de color verde la actina) y DAPI (tiñendo de color azul el núcleo de la célula y DNA bacterial). Con ayuda de un microscopio de fluorescencia se determinó lo siguiente:

FAS positivo. Membrana de la célula con puntos fluorescentes muy intensos y localizados.

FAS negativo. Presencia de las fibras sin intensidad de fluorescencia.

Como control positivo de polimerización de actina se utilizó la cepa EPEC E2348/69 y como control negativo la cepa E. coli C600.

\section{ENSAYO DE MOTILIDAD}

La motilidad de cada cepa fue examinada en medio SIM (Sulfide-Indol-Motility). Con un asa de siembra en punta se picó una colonia de placa MacConkey, luego se sembró en tubos de $3 \mathrm{~mL}$ de medio SIM, para incubarla por 24 horas a $37^{\circ} \mathrm{C}$. La lectura permitió clasificarlas como:
Cepas móviles. Aquellas que producían turbidez del medio y que se extienden más allá de la línea de siembra.

Cepas no móviles. Aquellas cuyo crecimiento se observó solamente en la línea de siembra.

\section{ANÁLISIS ESTADÍSTICO}

Se analizó los datos mediante un promedio general de las células encontradas por intervalos, se calculó la frecuencia y comparación a través de la prueba de Chi cuadrado $\left(\chi^{2}\right)$ con el programa Epi Info v.3.5. Para la comparación entre poblaciones se utilizó la prueba de Kruskal Wallis para determinar si existían diferencias entre los grupos evaluados. Se consideró un $p<0,05$ como significativo.

\section{RESULTADOS}

\section{ADHERENCIA DIFUSA A CÉLULAS HEp-2}

Las cualidades del fenotipo de adherencia, así como las diferencias entre las cepas que presentan este fenotipo, son comparadas en la Figura 1, donde se puede observar la cepa de EPEC (Figura 1A) de adherencia localizada (LA), que se manifiesta como una adherencia comunitaria de todas las bacterias en un mismo punto; mientras que la cepa prototipo DAEC-CG33 (Figura $1 B)$ presenta una adherencia bacteriana más aleatoria y alrededor de toda la célula y no en un solo punto como ocurre en la adherencia localizada. En la Figura 1C se observa una célula con bacterias E. coli C600, las cuales se caracterizan por ser no patogénicas y carecer de algún fenotipo de adherencia. Considerando estos puntos de identificación, pudimos observar que el patrón de adherencia difusa (DA) a células HEp-2 fueron observados en $22 / 25$ (88\%) cepas de diarrea y $6 / 6(100 \%)$ cepas de control.
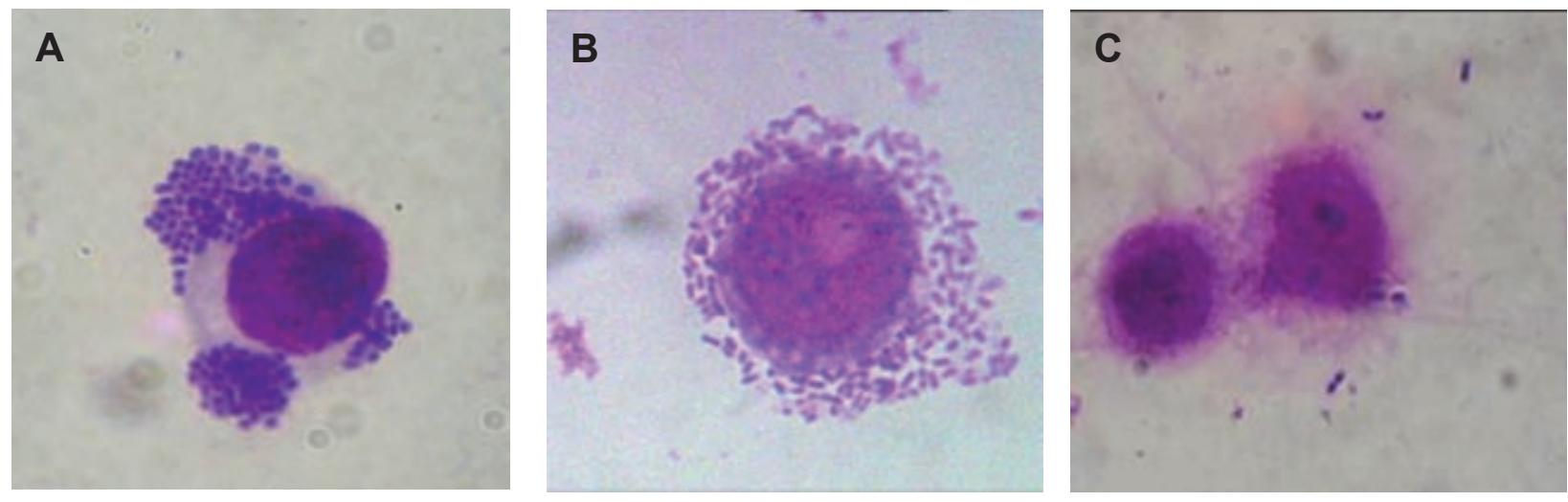

Figura 1. Patrones de adherencia en células HEp-2 (1000x). A) EPEC E2348/69, patrón de adherencia localizada (LA); B) cepa prototipo DAEC-CG33, patrón de Adherencia Difusa (DA); y C) sin adherencia, cepa C600 (no patogénica). 
Tabla 1. Distribución de bacterias adheridas a células HEp-2 y patrones observados.

\begin{tabular}{|c|c|c|c|c|c|c|c|c|c|c|c|}
\hline \multirow{3}{*}{$\begin{array}{l}\text { Cepas } \\
\text { Control }\end{array}$} & \multicolumn{8}{|c|}{ Bacterias adheridas $(\%)^{*}$} & \multicolumn{3}{|c|}{ Patrones observados } \\
\hline & \multicolumn{2}{|c|}{0} & \multicolumn{2}{|c|}{$1-50$} & \multicolumn{2}{|c|}{$51-100$} & \multicolumn{2}{|c|}{$>100$} & \multirow[t]{2}{*}{ DA } & \multirow[t]{2}{*}{ Motilidad } & \multirow[t]{2}{*}{ FAS } \\
\hline & & & & & & & & & & & \\
\hline D-0021 & 42,2 & $(14,1)$ & 240,7 & $(80,2)$ & 15,5 & $(5,2)$ & 1,7 & $(0,6)$ & + & + & - \\
\hline D-7041 & 12,8 & $(4,3)$ & 244,5 & $(81,5)$ & 33,8 & $(11,3)$ & 8,8 & $(2,9)$ & + & + & - \\
\hline D-0014 & 0 & & 195,8 & $(65,3)$ & 82,5 & $(27,5)$ & 21,7 & $(7,2)$ & + & + & - \\
\hline D-3114 & 0 & & 143,5 & $(47,8)$ & 85,0 & $(28,3)$ & 71,5 & $(23,8)$ & + & + & - \\
\hline D-3550 & 0 & & 202,5 & $(67,5)$ & 79,2 & $(26,4)$ & 18,3 & $(6,1)$ & + & + & - \\
\hline D-7110 & 0 & & 223,7 & $(74,6)$ & 66,0 & $(22,0)$ & 10,3 & $(3,4)$ & + & + & + \\
\hline \multicolumn{12}{|l|}{ Diarrea } \\
\hline D-0030 & 0 & & 214,2 & $(71,4)$ & 71,0 & $(23,7)$ & 14,8 & $(4,9)$ & + & + & + \\
\hline D-3044 & 0 & & 98,8 & $(32,9)$ & 145,7 & $(48,6)$ & 55,5 & $(18,5)$ & + & + & + \\
\hline D-0089 & 0 & & 234,7 & $(78,2)$ & 52,3 & $(17,4)$ & 13,0 & $(4,3)$ & + & + & + \\
\hline D-7197 & 87,0 & $(29,0)$ & 204,0 & $(68,0)$ & 8,2 & $(2,7)$ & 0,8 & $(0,3)$ & + & + & + \\
\hline D-0011 & 14,3 & $(4,8)$ & 264,0 & $(88,0)$ & 20,0 & $(6,7)$ & 1,7 & $(0,6)$ & + & + & + \\
\hline D-3137 & 6,3 & $(2,1)$ & 180,0 & $(60,0)$ & 59,5 & $(19,8)$ & 54,2 & $(18,1)$ & + & + & + \\
\hline D-3100 & 72,8 & $(24,3)$ & 225,2 & $(75,1)$ & 2,0 & $(0,7)$ & 0 & & + & + & + \\
\hline D-5001 & 82,5 & $(27,5)$ & 217,5 & $(72,5)$ & 0 & & 0 & & + & + & + \\
\hline D-7100 & 0 & & 252,8 & $(84,3)$ & 42,7 & $(14,2)$ & 4,5 & $(1,5)$ & + & + & - \\
\hline D-0185 & 0 & & 237,5 & $(79,2)$ & 49,7 & $(16,6)$ & 12,8 & $(4,3)$ & + & + & - \\
\hline D-7202 & 0 & & 250,2 & $(83,4)$ & 44,8 & $(14,9)$ & 5,0 & $(1,7)$ & + & + & - \\
\hline D-3042 & 25,7 & $(8,6)$ & 262,8 & $(87,6)$ & 11,5 & $(3,8)$ & 0 & & + & + & - \\
\hline D-0092 & 29,3 & $(9,8)$ & 251,8 & $(83,9)$ & 18,8 & $(6,3)$ & 0 & & + & + & - \\
\hline D-0072 & 20,3 & $(6,8)$ & 227,0 & $(75,7)$ & 42,5 & $(14,2)$ & 10,2 & $(3,4)$ & + & - & + \\
\hline D-3388 & 19,8 & $(6,6)$ & 271,0 & $(90,3)$ & 9,2 & $(3,1)$ & 0 & & + & - & + \\
\hline D-3041 & 25,8 & $(8,6)$ & 250,2 & $(83,4)$ & 22,5 & $(7,5)$ & 1,5 & $(0,5)$ & + & - & + \\
\hline D-7153 & 78,3 & $(26,1)$ & 187,3 & $(62,4)$ & 31,8 & $(10,6)$ & 2,5 & $(0,8)$ & + & - & + \\
\hline D-5003 & 0 & & 214,2 & $(71,4)$ & 75,8 & $(25,3)$ & 10,0 & $(3,3)$ & + & - & + \\
\hline D-3051 & 0 & & 265,7 & $(88,6)$ & 29,5 & $(9,8)$ & 4,8 & $(1,6)$ & + & - & + \\
\hline D-0018 & 94,0 & $(31,3)$ & 204,8 & $(68,3)$ & 1,2 & $(0,4)$ & 0 & & + & - & + \\
\hline D-5003 & 8,4 & $(2,8)$ & 248,8 & $(82,9)$ & 39,0 & $(13,0)$ & 3,8 & $(1,3)$ & + & - & - \\
\hline D-5030 & 32,7 & $(10,9)$ & 267,3 & $(89,1)$ & 0 & & 0 & & + & - & - \\
\hline D-7220 & 33,2 & $(11,1)$ & 266,8 & $(88,9)$ & 0 & & 0 & & - & + & - \\
\hline D-0070 & 259,5 & $(86,5)$ & 40,5 & $(13,5)$ & 0 & & 0 & & - & + & - \\
\hline D-3347 & 106,3 & $(35,4)$ & 193,7 & $(64,6)$ & 0 & & 0 & & - & - & - \\
\hline \multicolumn{12}{|c|}{ DAEC (cepa prototipo) } \\
\hline GC33 & 0 & & 223,8 & $(74,6)$ & 64,8 & $(21,6)$ & 11,3 & $(3,8)$ & + & + & + \\
\hline
\end{tabular}

*Promedio de 6 lecturas por cepa; DA: adherencia difusa; FAS: tinción fluorescente para actina.

\section{CUANTIFICACIÓN DE ADHERENCIA A CÉLULAS HEp-2}

La categorización de las células según la cantidad de bacterias adheridas como: cero bacterias por célula ( $\mathrm{Fi}$ gura 2A), de 1 a 50 bacterias por célula (Figura 2B), de 50 a 100 bacterias por célula (Figura 2C), >100 bacterias por célula (Figura 2D) permitieron la cuantificación (Tabla 1), observando una adherencia leve $(<50$ bacterias/célula) en $87 \%$ de muestras de diarrea y moderada ( $>50$ bacterias/célula) en $72,5 \%$ de muestras control (Figura 3 ).
Se realizó una homogenización de los datos mediante una media geométrica y se usó la prueba de KruskalWallis, encontrando que las poblaciones de control y diarrea difieren en su distribución de bacterias adheridas a las células $(p<0,05)$.

\section{PRUEBA DE FAS \\ (TINCIÓN FLUORESCENTE PARA ACTINA)}

En 15 de los 25 casos de diarrea (60\%) y uno de los seis casos de control $(16,7 \%)$ fueron positivos para la prueba 

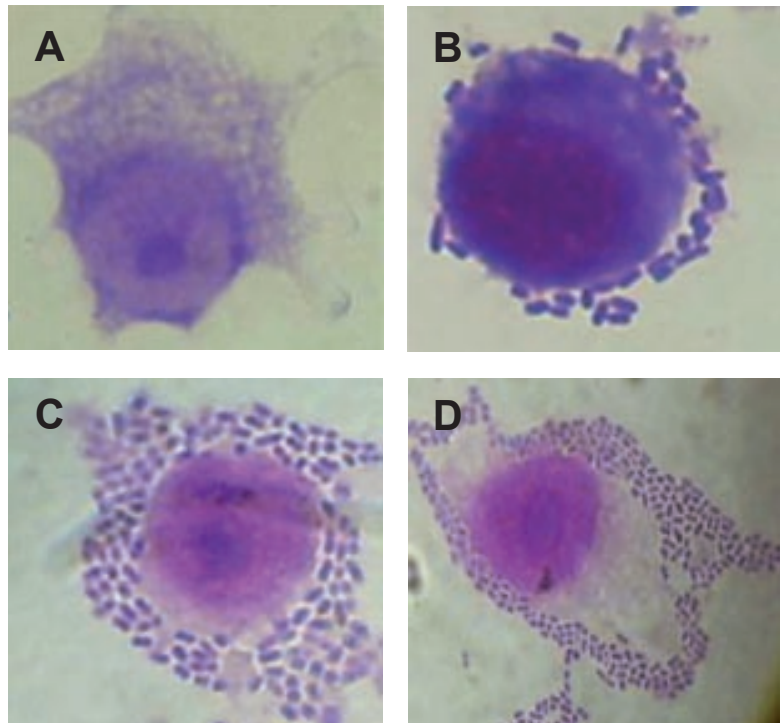

Figura 2. Categorización de las células según bacterias adheridas (1000x) como: A) 0, B) 1-50, C) 50-100 y D) >100 bacterias/célula.

de FAS (Figura 4). Al mismo tiempo, se realizó un conteo de las células que presentaban esta fluorescencia (203 \pm 69 ) en diarrea frente al control (69 \pm 23$)$. Además se observó ramificaciones muy notorias.
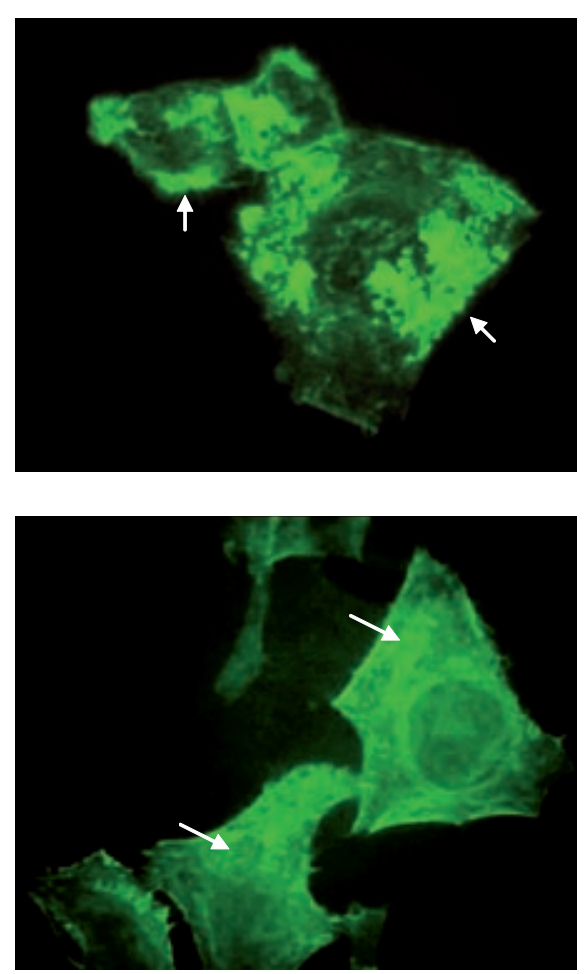

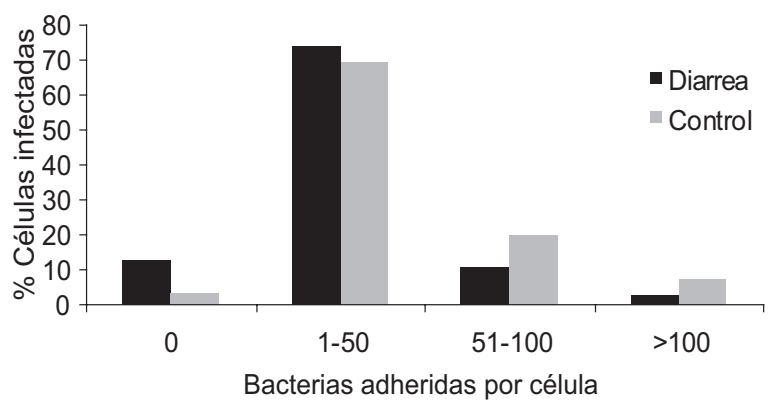

Figura 3. Frecuencia de bacterias adheridas por célula según cepas de diarrea y controles sanos.

\section{ENSAYO DE MOTILIDAD}

Todas las cepas control fueron móviles, a diferencia de cepas de diarrea donde solo el $60 \%$ fue móvil.

\section{ANÁLISIS COMPARATIVO DE LOS PATRONES DE ADHERENCIA EN MUESTRAS DE DIARREA Y CONTROL}

Se comparó la distribución de las cepas de diarrea y control según la asociación de adherencia, polimerización de actina y motilidad, encontrando que las cepas control
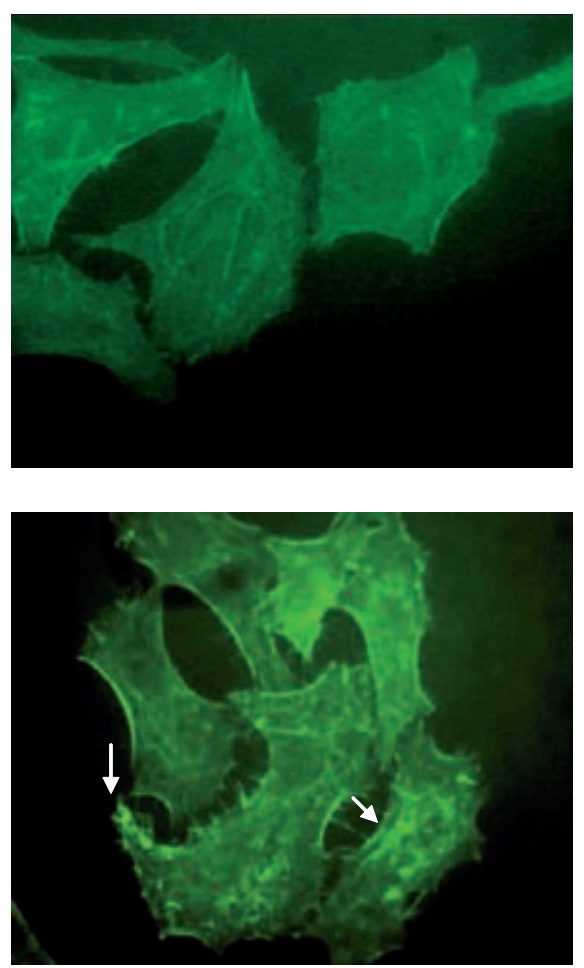

Figura 4. Prueba de FAS en células HEp-2 e infectadas con A) EPEC E2348/69 control FAS positivo (FAS +) (LA) B) cepa C600 control FAS negativo (FAS-) C) cepa prototipo DAEC-CG33, FAS+ D) Cepa DAEC de diarrea con acumulación de actina del citoesqueleto (flechas blancas) inducido por la infección (400x). 
Tabla 2. Correlación del patrón de adherencia, FAS y motilidad en cepas DAEC de diarrea y control.

\begin{tabular}{|c|c|c|c|c|c|c|c|}
\hline \multicolumn{3}{|c|}{ Característica } & \multicolumn{2}{|c|}{ Diarrea } & \multicolumn{2}{|c|}{ Control } & \multirow{2}{*}{ p } \\
\hline DA & FAS & Motilidad & $\mathbf{n}$ & $(\%)$ & $\mathbf{n}$ & (\%) & \\
\hline+ & + & + & $8 / 22$ & $(36,4)$ & $1 / 6$ & $(16,7)$ & -- \\
\hline+ & + & - & $7 / 22$ & $(28,0)$ & & -- & -- \\
\hline+ & - & + & $5 / 22$ & $(22,7)$ & $5 / 6$ & $(83,3)$ & $<0,05$ \\
\hline+ & - & - & $2 / 22$ & $(9,1)$ & & -- & -- \\
\hline- & - & + & $2 / 3$ & $(66,7)$ & & -- & -- \\
\hline- & - & - & $1 / 3$ & $(33,3)$ & & -- & -- \\
\hline
\end{tabular}

DA: adherencia difusa; FAS: tinción fluorescente para actina.

se encuentran asociadas a la adherencia con motilidad y sin polimerización (Tabla 2).

\section{DISCUSIÓN}

En el presente trabajo se observó que $88 \%$ de cepas DAEC identificadas por PCR presentaron el fenotipo de adherencia difusa, lo cual sustenta el reconocimiento del método de PCR como rápido, sensible, específico y barato para la detección de $E$. coli diarrogénicas. Esta técnica reconoce al gen daaD, el cual es el gen mejor conservado entre los genes relacionados a la adhesina Dr. Servin ${ }^{(14)}$ indica que este gen pertenece a una secuencia conservada que está dirigida por un operon daa, el cual comanda la secreción de la adhesina F1845 uno de los miembros de la familia de adhesinas $\mathrm{Dr}$, el cual pertenece al conjunto de DAEC Afa/Dr típicas, subclase 1 debido a su unión con el receptor antigeno carcinoembrionario (CEA) ${ }^{(15)}$.

No encontramos diferencias significativas entre la presencia de cepas provenientes de niños con y $\sin$ diarrea y la frecuencia de la adherencia difusa; sin embargo, estudios realizados en México, Chile, Nueva Caledonia y Perú reportan un mayor porcentaje de DAEC aisladas de muestras diarreicas que de muestras control en niños ${ }^{(12,16-18)}$. No obstante, estudios realizados en Francia y Brasil, no encontraron una asociación entre adherencia difusa y la presencia de diarrea (1921). Esta controversia probablemente incluye a clones patogénicos y no patogénicos.

La ausencia de adherencia en $22 \%$ de nuestras cepas puede deberse, como indica Nataro ${ }^{(22)}$, a que si bien la adhesión a la superficie celular es considerada un paso esencial para el desencadenamiento de enfermedades entéricas, otras proteínas de virulencia pueden ser responsables de la enfermedad, considerando que este sexto grupo ahora reconocido entre las $E$. coli diarrogénicas es un grupo heterogéneo que hasta nuestros días sigue siendo materia de investigación.
En este estudio se describe los patrones de adherencia observados en la interacción de cepas DAEC con cultivos celulares HEp-2, encontrando que la mayor población de bacterias adheridas fue menor a 50 por célula, lo cual fue asociado significativamente con cepas de diarrea. Muchos estudios reportan el tipo de adherencia que acompaña a estas cepas; sin embargo, pocos estudios evalúan la cantidad de bacterias que forman parte de este fenotipo. Beinke et al. ${ }^{(23)}$ evaluaron cepas causantes de diarrea identificadas como DAEC según su patrón de adherencia, presencia de genes asociados con la familia de adhesinas Dr y la ausencia de marcadores genéticos de otras $E$. coli diarreogénicas, observando que estas cepas promovieron el fenotipo de adherencia y efacelamiento $(A / E)$, secreción de proteínas homólogas de Esp (proteínas secretadas por EPEC) y acumulación de actina en sitios de unión de la bacteria.

Las cepas DAEC positivas para FAS, en comparación con microcolonias de la cepa EPEC 2348/69, se unen en una proporción más baja de manera difusa, lo que parecería proporcionar las condiciones necesarias para la transferencia de señales que conduzcan a la acumulación de actina en sus sitios de fijación. En este mismo estudio Beinke et al. ${ }^{(23)}$ encontraron que las cepas DAEC de muestras control produjeron acumulación de actina en menor proporción que las cepas de muestras de diarrea.

En un estudio con una cepa DAEC aislada de un niño con diarrea, que hibridizó con una sonda de DNA F1845, Yamamoto et al. (24) observaron la adherencia a células HEp-2, sugiriendo la posibilidad de que las bacterias DAEC provocan la acumulación de actina. En nuestro caso, las cepas DAEC presentaron acumulación de actina en $60 \%$ de las cepas de diarrea en comparación a $16,7 \%$ en muestras control, lo que indica que no todas las DAEC inducen la acumulación de actina y por ende el daño o lesión.

Estudios previos ${ }^{(25,26)}$ han demostrado que DAEC Afa/Dr promueven el desamblaje de F-actina, villina y frimbrina, que son proteínas que desempeñan papeles clave en las microvellosidades. Un estudio de Peiffer et al. (27), en células intestinales no diferenciadas INT407 y células Caco-2 totalmente diferenciadas expresando DAF, demostraron que la infección con la cepa prototipo C1845 y $E$. coli recombinante llevando los plásmidos codificantes de la adhesina fimbrial F1845 y adhesina Dr provocaron dramáticos reordenamientos de F-actina además de la agrupación de fosfotirosinas y la activación de una cascada de señalización de moléculas, incluyendo la proteína tirosina quinasa, fosfolipasa $\mathrm{C}$, fosfatidilinositol 3-quinasa y la proteína quinasa $\mathrm{C}$, y un aumento de la concentración de calcio. 
Actualmente, se considera que la motilidad mediada por los flagelos contribuye a la virulencia en las bacterias Gram negativas. Un caso particular es el flagelo de EPEC que está directamente involucrado en la adhesión de estas bacterias (28). En nuestro estudio todas las cepas control fueron motiles, a diferencia de las cepas de diarrea $(60 \%)$, no obstante, este análisis está limitado por un reducido número de cepas control. Curiosamente, Arikawa et al. ${ }^{(29)}$, ha notificado recientemente que cepas E. coli Dr y F1845 móviles fueron capaces de inducir la producción de IL-8 a diferencia de las cepas no móviles, lo que sugiere que el flagelo desempeña un papel importante en DAEC Afa/Dr que indujeron respuestas proinflamatorias ${ }^{(23)}$. Una hipótesis que explicaría estas diferencias, y que no excluiría otras, es que existe variación dependiente de la edad en la expresión de receptores de membrana que se desarrollan en el epitelio intestinal humano para las adhesinas Afa/Dr, que a su vez modula la colonización intestinal por DAEC Afa/Dr y la adhesina dependiente de las lesiones estructurales y funcionales en las células intestinales.

En conclusión, $88 \%$ de las cepas de diarrea y $100 \%$ de las cepas control presentaron adherencia difusa, mientras que 60 y $17 \%$ respectivamente presentaron polimerización de actina y 60 y $100 \%$ respectivamente, presentaron motilidad. En general, las poblaciones de diarrea y control presentaron una diferencia significativa en el número de bacterias adheridas por célula. Una limitación de este estudio es el reducido número de cepas control para una adecuada comparación. Por otro lado, no se ha realizado una caracterización molecular de las cepas estudiadas, para determinar la variación de genes de virulencia en cada grupo. Adicionalmente, el ensayo de motilidad debe ser evaluado por parámetros más robustos que permitan sostener la teoría de su participación como factor de virulencia. Sin embargo, este estudio presenta la primera caracterización de patrones de adherencia de cepas DAEC aisladas de niños peruanos. Se requieren estudios adicionales con mayor número de cepas y la caracterización molecular de las mismas.

\section{AGRADECIMIENTOS}

A Martín Montes, Elsa González, Téofilo Quispe Chullo del Instituto de Medicina Tropical Alexander von Humboldt (IMTAvH) y en especial a César Cárcamo de Facultad de Salud Pública y Administración "Carlos Vidal Layseca" de la Universidad Peruana Cayetano Heredia (UPCH) por su colaboración en el análisis de los resultados del presente artículo. A Claudio F. Lanata, Ana Gil y Lucie Ecker, quienes junto con Theresa J. Ochoa condujeron el estudio de cohorte en el Cono Sur de Lima. De igual manera, a todos los integrantes del Laboratorio de Enfermedades Entéricas y Nutrición del IMTVH, UPCH.

\section{Fuentes de Financiamiento}

Este trabajo ha sido financiado por el grant 1K01TW007405 otorgado a la doctora Theresa J. Ochoa.

\section{Conflictos de Interés}

Los autores declaran no tener ningún conflicto de interés en la publicación de este artículo.

\section{REFERENCIAS BIBLIOGRÁFICAS}

1. O’Ryan M, Prado V, Pickering LK. A millennium update on pediatric diarrheal illness in the developing world. Semin Pediatr Infect Dis. 2005;16(2):125-36.

2. Bryce J, Boschi-Pinto C, Shibuya K, Black RE, WHO Child Health Epidemiology Reference Group. WHO Estimates of the causes of death in children. Lancet. 2005;365:1147-52.

3. Nataro JP, Kaper JB, Robins-Browne R, Prado V, Vial P, Levine MM. Patterns of adherence of diarrheagenic Escherichia coli to HEp-2 cells. Pediatr Infect Dis J. 1987;6(9):829-31.

4. Torres AG, Zhou X, Kaper JB. Adherence of diarrheagenic Escherichia coli strains to epithelial cells. Infect Immun. 2005;73(1):18-29.

5. Lopes LM, Fabbricotti SH, Ferreira AJ, Kato MA, Michalski J, Scaletsky IC. Heterogeneity among strains of diffusely adherent Escherichia coli isolated in Brazil. J Clin Microbiol. 2005;43(4):1968-72.

6. Donnenberg MS, Nataro JP. Methods for studying adhesion of diarrheagenic Escherichia coli. Methods Enzymol. 1995;253:324-36.

7. Cookson S, Nataro J. Characterization of HEp-2 cell projection formation induced by diffusely adherent Escherichia coli. Microb Pathog. 1996;21(6):421-34.

8. Peiffer I, Guignot J, Barbat A, Carnoy C, Moseley SL, Nowicki BJ, et al. Structural and functional lesions in brush border of human polarized intestinal Caco-2/TC7 cells infected by members of the Afa/Dr diffusely adhering family of Escherichia coli. Infect Immun. 2000;68(10):5979-90.

9. Knutton S, Baldwin T, Williams PH, McNeish AS. Actin accumulation at sites of bacterial adhesion to tissue culture cells: basis of a new diagnostic test for enteropathogenic and enterohemorrhagic Escherichia coli. Infect Immun. 1989;57(4):1290-8

10. Mustafa I, Arikawa, Ogasawara K, Nakamura $H$, Ogasawar J, Hase A, et al. Association of IL-8-inducing strains of diffusely adherent Escherichia coli with sporadic diarrheal patients with less than 5 years of age. Braz $\mathrm{J}$ Infect Dis. 2007;11(1):44-9.

11. Guion CE, Ochoa TJ, Walker CM, Barletta F, Cleary TG. Detection of diarrheagenic Escherichia coli by use of melting-curve analysis and real-time multiplex PCR. J Clin Microbiol. 2008;46(5):1752-7. 
12. Ochoa TJ, Ecker L, Barleta F, Mispireta M, Gil A, Contreras C, et al. Age-related susceptibility to infection with diarrheagenic Escherichia coli among infants from periurban areas in Lima, Peru. Clin Infect Dis. 2009;49(11):1694-702.

13. Knutton S, Phillips AD, Smith HR, Gross RJ, Shaw R, Watson P, et al. Screening for enteropathogenic Escherichia coli in infants with diarrhea by the fluorescent-actin staining test. Infect Immun. 1991;59(1):365-71.

14. Servin A. Pathogenesis of $A f a / D r$ diffusely adhering Escherichia coli. Clin Microbiol Rev. 2005;18(2):264-92.

15. Nowicki B, Selvarangan R, Nowicki S. Family of Escherichia coli Dr adhesins: decay-accelerating factor receptor recognition and invasiveness. J Infect Dis. 2001;183(Suppl 1):S24-7.

16. Girón JA, Jones T, Millán-Velasco F, Castro-Muñoz E, Zárate L, Fry J, et al. Diffuse-adhering Escherichia coli (DAEC) as a putative cause of diarrhea in Mayan children in Mexico. J Infect Dis. 1991;163(3):507-13.

17. Levine MM, Ferreccio C, Prado V, Cayazzo M, Abrego $\mathbf{P}$, Martinez, J, et al. Epidemiologic studies of Escherichia coli diarrheal infections in a low socioeconomic level periurban community in Santiago, Chile. Am J Epidemiol. 1993;138(10):849-69.

18. Germani Y, Begaud E, Duval P, Le Bouguenec C. Prevalence of enteropathogenic, enteroaggregative, and diffusely adherent Escherichia coli among isolates from children with diarrhea in New Caledonia. J Infect Dis. 1996;174(5):1124-6.

19. Gomes T, Blake P, Travulsi LR. Prevalence of Escherichia colistrains with localized, diffuse, and aggregative adherence to HeLa cells in infants with diarrhea and matched controls. J Clin Microbiol. 1989;27(2):266-9.

20. Poitrineau P, Forestier C, Meyer M, Jallat C, Rich C, Malpuech G, et al. Retrospective case-control study of diffusely adhering Escherichia coli and clinical features in children with diarrhea. J Clin Microbiol. 1995;33(7):1961-2.

21. Forestier C, Meyer M, Favre-Bonte S, Rich C, Malpuech $\mathbf{G}$, Le Bouguenec $\mathbf{C}$, et al. Enteroadherent Escherichia coli and diarrhea in children: a prospective case-control study. J Clin Microbiol. 1996;34(12):2897-903.

22. Nataro JP, Kaper JB. Diarrheagenic Escherichia coli. Clin Microbiol Rev. 1998; 11(1):142-201.

23. Beinke C, Laarmann S, Wachter C, Karch H, Greune L, Schmidt MA. Diffusely adhering Escherichia coli strains induce attaching and effacing phenotypes and secrete homologs of Esp proteins. Infect Immun. 1998;66(2):528-39.
24. Yamamoto T, Kaneko M, Changchawalit S, Serichantalergs $\mathbf{O}$, ljuin S, Echeverria P. Actin accumulation associated with clustered and localized adherence in Escherichia coli isolated from patients with diarrhea. Infect Immun. 1994;62(7):2917-29.

25. Guignot J, Breard J, Bernet-Camard MF, Peiffer I, Nowicki BJ, Servin AL, et al. Pyelonephritogenic diffusely adhering Escherichia coli EC7372 harboring Dr-Il adhesin carries classical uropathogenic virulence genes and promotes cell lysis and apoptosis in polarized epithelial Caco-2/TC7 cells. Infect Immun. 2000;68(12):7018-27.

26. Bernet-Camard MF, Coconnier MH, Hudault S, Servin AL. Pathogenicity of the diffusely adhering strain Escherichia coli C1845: F1845 adhesin-decay accelerating factor interaction, brush border microvillus injury, and actin disassembly in cultured human intestinal epithelial cells. Infect Immun. 1996;64(6):1918-28.

27. Peiffer I, Servin AL, Bernet-Camard MF. Piracy of decayaccelerating factor (CD55) signal transduction by the diffusely adhering strain Escherichia coli C1845 promotes cytoskeletal F-actin rearrangements in cultured human intestinal INT407 cells. Infect Immun. 1998;66(9):4036-42.

28. Girón JA, Torres AG, Freer E, Kaper JB. The flagella of enteropathogenic Escherichia coli mediate adherence to epithelial cells. Mol Microbiol. 2002;44(2):361-79.

29. Arikawa K, Meraz IM, Nishikawa Y, Ogasawara J, Hase A. Interleukin-8 secretion by epithelial cells infected with diffusely adherent Escherichia coli possessing afa adhesincoding genes. Microbiol Immunol. 2005; 49(6):493-503.

30. Betis F, Brest P, Hofman V, Guignot J, Kansau I, Rossi $\mathbf{B}$, et al. Afa/Dr diffusely adhering Escherichia coli infection in T84 cell monolayers induces increased neutrophil transepithelial migration, which in turn promotes cytokinedependent upregulation of decayaccelerating factor (CD55), the receptor for Afa/Dr adhesins. Infect Immun. 2003;71(4):1774-83.

Correspondencia: Theresa J.Ochoa.

Dirección: Av. Honorio Delgado 430, San Martin de Porras, Lima 33, Perú.

Teléfono: (511) 482-3903; Fax (511) 482-3404.

Correo electrónico: Theresa.J.Ochoa@uth.tmc.edu; Theresa. Ochoa@upch.pe

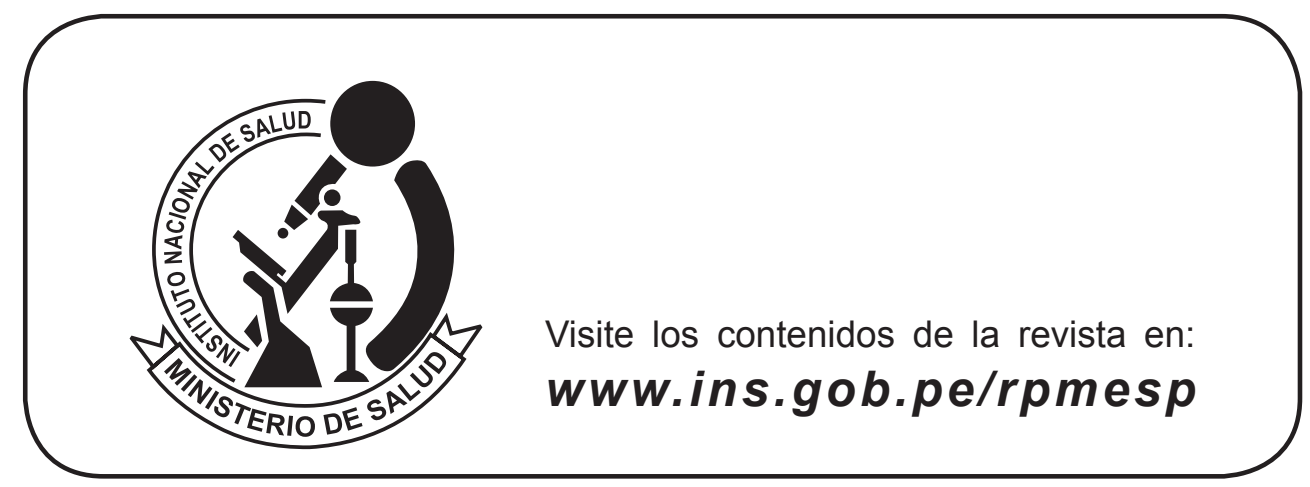

